\title{
Sjögren syndrome: A case report
}

\author{
C. Dellafiore*, A. Villa, F. Zibera
}

IRCCS Foundation, San Matteo Medical Center, Institute of Radiology, University of Pavia, Italy

\section{KEYWORDS}

Sjögren syndrome;

Salivary glands;

Sonography.

\section{Introduction}

Sjögren syndrome is a systemic autoimmune disorder that affects the exocrine glands. It is characterized by the

\begin{abstract}
Sjögren syndrome is a systemic autoimmune disorder that affects the exocrine glands. The authors present the case of a 50-year-old woman diagnosed with this syndrome on the basis of clinical and serological findings. Sonography of the major salivary glands revealed normal-sized glands with echo structures that were diffusely inhomogeneous due to the presence of multiple hypoechoic areas. Parenchymal vascularization was significantly increased on color Doppler imaging. These findings confirmed the diagnosis and revealed active disease manifested by glandular hypervascularization. This represents a typical case of Sjögren syndrome and illustrates the diagnostic value in these cases of salivary gland sonography, which is effective, noninvasive, and repeatable and provides accurate information on the vascularization status of the glands.
\end{abstract}

Sommario La sindrome di Sjögren è una malattia autoimmune, sistemica, coinvolgente le ghiandole esocrine. Presentiamo il caso di una paziente, A.G., 50 anni, giunta alla nostra osservazione con diagnosi di Sindrome di Sjögren, sulla base della sintomatologia e degli esami ematochimici. Ecograficamente le ghiandole salivari maggiori erano nei limiti di norma per dimensioni, presentavano diffusa disomogeneità ecostrutturale bilateralmente per la presenza di multiple areole ipoecogene e vascolarizzazione parenchimale significativamente aumentata. L'ecografia confermava quindi la diagnosi ed evidenziava ipervascolarizzazione delle ghiandole, segno di attività della malattia. Abbiamo ritenuto il caso meritevole di segnalazione perché tipico e per sottolineare come la valutazione ecografica delle ghiandole salivari nella sindrome di Sjögren sia efficace, poco invasiva, facilmente ripetibile e permetta, un'accurata valutazione della vascolarizzazione ghiandolare.

(C) 2012 Elsevier Srl. All rights reserved.

\footnotetext{
* Corresponding author.

E-mail address: carolina.dellafiore@libero.it (C. Dellafiore).
} 

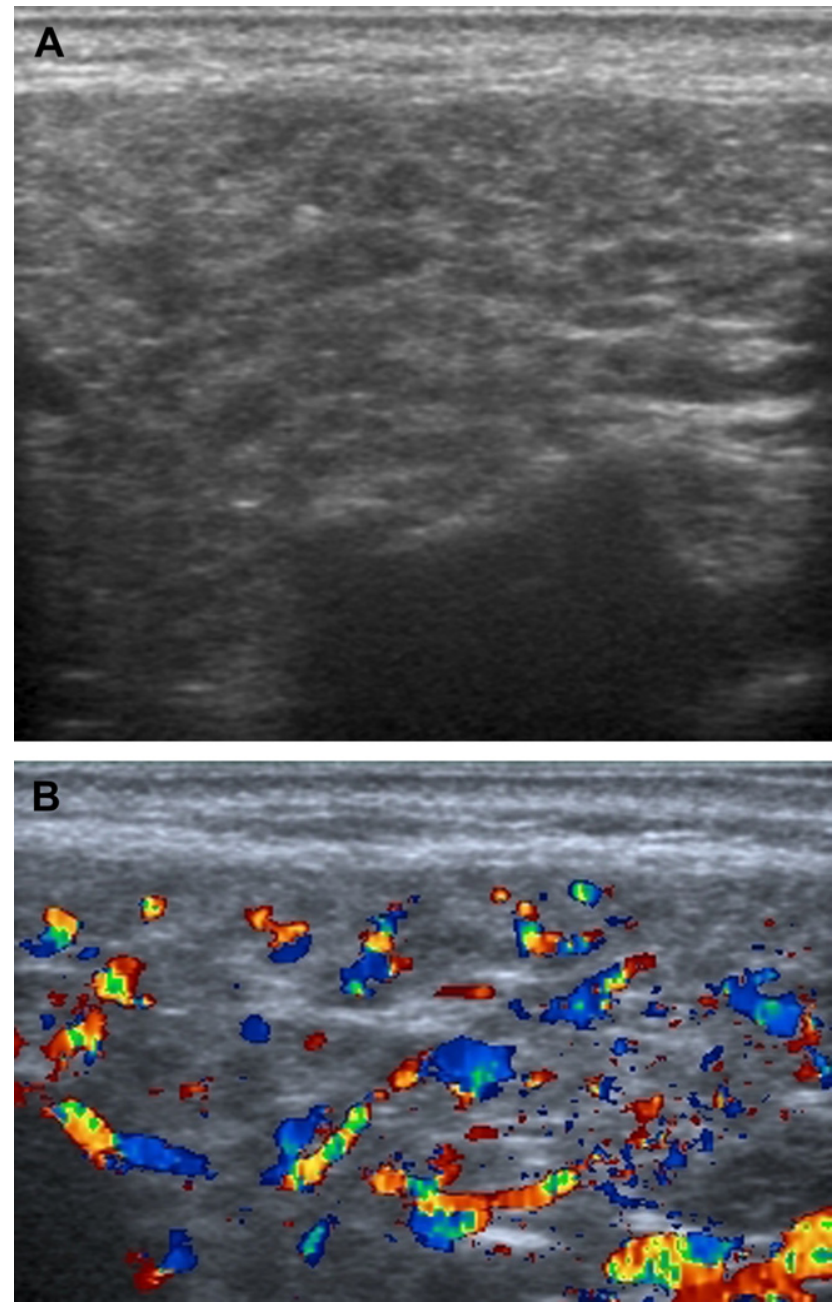

Figure 1 Right parotid gland: (A) B-mode sonography reveals a diffusely dishomogeneous gland containing multiple areas of hypoechogenicity. (B) Hypervascularization is evident on color Doppler imaging.

associated with other autoimmune diseases (rheumatoid arthritis, lupus erythematosus, scleroderma, inflammatory vascular and connective tissue diseases, etc.). The syndrome is most common diagnosed in women between the ages of 40 and 50 (female:male ratio of 9:1). The diagnosis is generally based on the results of salivary and/or lachrymal gland biopsies, examination of the oral cavity and eyes, and autoantibody assays. Ultrasonography can be used to confirm the diagnosis.

\section{Case report}

The patient was a 50-year-old woman with newly diagnosed Sjögren syndrome. She was positive for anti-SSA and antiSSB autoantibodies and presented with stinging of the eyes, the sensation of a foreign body in the eye, and reduced salivary secretion (dryness of the mouth and altered sense of taste).

On sonography, the major salivary glands appeared to be normal-sized with diffusely inhomogeneous echo structures bilaterally and multiple areas of hypoechogenicity, thereby confirming the diagnosis of Sjögren syndrome. Color Doppler imaging revealed substantially increased parenchymal vascularization [Figs. 1 and 2] indicative of intense inflammatory activity.

The patient provided informed consent to the publication of this report.

\section{Discussion}

According to the European Community Study Group, the diagnosis of Sjögren syndrome should be based on the results of: 1) biopsies of the minor salivary glands and/or lachrymal glands; 2) examination of the oral cavity consisting of sialography or the Saxon test (in which a sponge is chewed for 2 min by the patient and then weighed) combined with salivary-gland scintigraphy; eye examination consisting of the Schirmer test plus the Bengal rose test or the fluorescein test; and 4) assays for anti-Ro/SSA or anti-La/SSB antibodies [1,2].

For a definitive diagnosis, at least two of the four criteria must be met.
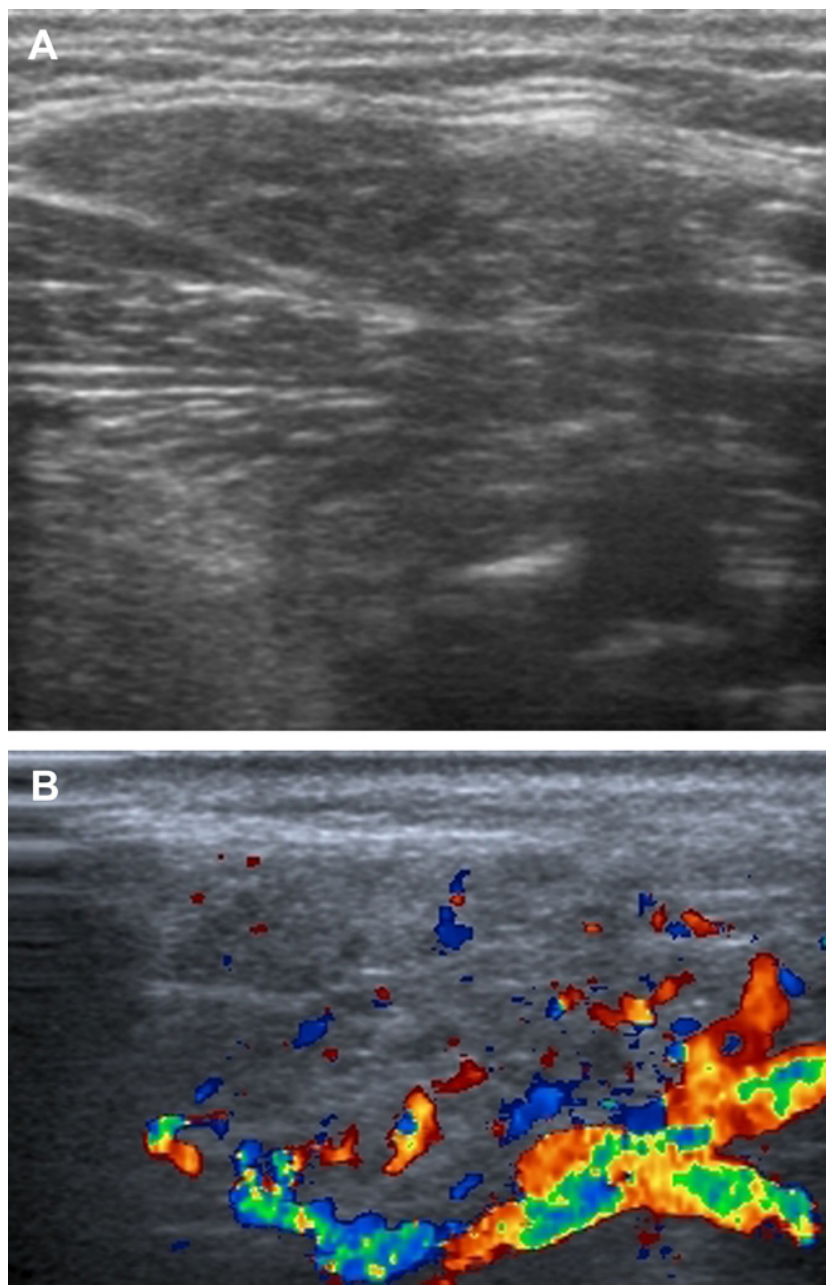

Figure 2 Right submandibular area. (A) B-mode sonography reveals a diffusely dishomogeneous gland with multiple areas of hypoechogenicity (similar to that of the parotid gland in Fig. 1). (B) Hypervascularization is evident on color Doppler imaging. 
Table 1 Scoring systemic for sonographic changes in the major salivary glands in primary Sjögren syndrome developed by Hočevar et al.

1 Parenchymal echogenicity relative to that of the thyroid (isoechoic 0 ; hypoechoic 1 );

2 Glandular homogeneity (0 homogeneous; 1 mild inhomogeneity; 2 obvious inhomogeneity; 3 marked inhomogeneity);

3 Presence of hypoechoic areas (0 absent, 1, a few, scattered; 2 , several; 3 , numerous)

4 Hyperechogenic foci in the parotid glands (0 absent, 1, a few, scattered; 2 , several; 3 , numerous) or submandibular area ( 0 none, 1 present);

5 Salivary gland borders ( 0 , clear, regular defined borders; 1 , partly defined borders; 2 , ill-defined borders; 3 , borders not visible).

Biopsy of the minor salivary glands is highly specific for Sjögren syndrome if the sample includes 5-10 glands and the connective tissues surrounding them. In recent years, however, MR-sialography and sonographic assessment of the major salivary glands have been playing increasingly important roles. Because they are noninvasive, they are better tolerated by the patient, and they are [3].

MR-sialography is highly effective when used with sonography, particularly in the study of excretory ducts. MR imaging exploits the naturally hyperintense signal of the saliva and allows 3D reconstruction, providing excellent full-length visualization of the ducts, including the distal portion of the Wharton duct. In Sjogren syndrome, there are bee-hive or cystic alterations that are hypointense in T1-weighted sequences and hyperintense on long TR images.

Several sonographic systems have been proposed to stage Sjögren syndrome, including those developed by Salaffi in 2000 [4] and by Niemalä in 2004 [3].

Recently, Hočevar et al. developed a new classification system based on the following five variables: echogenicity of the salivary gland parenchyma relative to the thyroid gland, glandular homogeneity, presence of hypoechoic areas, possible hyperechoic foci at the parotid and submandibular levels, and glandular margins (Table 1) [5].

More substantial operator-dependent variability has been documented in the assessment of items 4 and 5 . Scores range from 0 to 48, and the cut-off for diagnosis of the syndrome is 17 . In our opinion, glandular vascularization is another useful parameter to evaluate. Although it is not one of the criteria used for staging, it provides information on the inflammatory status of the gland [6].

\section{Conclusions}

Sjögren syndrome is a systemic autoimmune disease that affects the exocrine glands. Diagnosis of the syndrome is generally based on biopsy of the minor salivary glands and/or lachrymal glands, examination of the oral cavity and eyes, and autoantibody positivity. More recently, MRsialography and ultrasound studies of the major salivary glands have been playing more important roles because they are noninvasive and easily repeatable. Various criteria have been assessed for classification of sonographic findings: the most recent approach focuses on the echogenicity of the salivary gland parenchyma relative to that of the thyroid, glandular homogeneity, the presence of hypoechoic areas, parotid and submandibular foci of hyperechogenicity, and characteristics of the margins of the salivary glands. Sonographic exploration of the salivary glands in patients with Sjögren syndrome is effective, noninvasive, and highly repeatable. It provides accurate information on the vascularization of the glands, which reflects the activity of the disease.

\section{Conflict of interest}

The authors have no conflict of interest to disclose.

\section{Appendix A. Supplementary material}

Supplementary material associated with this article can be found, in the online version, at doi:10.1016/j.jus.2012. 03.003 .

\section{References}

[1] Obinata K, Sato T, Ohmori K, Shindo M, Nakamura M. A comparison of diagnostic tools for Sjögren syndrome, with emphasis on sialography, histopathology and ultrasonography. Oral Surg Oral Med Oral Pathol Oral Radiol Endod 2010;109: 129-34.

[2] Takagi $Y$, Kimura $Y$, Nakamura $H$, Sasaki M, Eguchi $K$, Nakamura T. Salivary gland ultrasonography: can it be an alternative to sialography as an imaging modality for Sjögren's syndrome? Ann Rheum Dis 2010;69:1321-4.

[3] Niemelä RK, Takalo R, Pääkkö E, Suramo I, Päivänsalo M, Salo T, et al. Ultrasonography of salivary glands in primary Sjögren's syndrome. A comparison with magnetic resonance imaging and magnetic resonance sialography of parotid glands. Rheumatology 2004;43:875-9.

[4] Salaffi F, Peroni M, Ferraccioli GF. Discriminating ability of composite indices for measuring disease activity in rheumatoid arthritis: a comparison of the Chronic Arthritis Systemic Index, Disease Activity Score and Thompson's articular index. Rheumatology (Oxford) 2000 Jan;39(1):90-6.

[5] Hocevar A, Rainer S, Rozman B, Zor P, Tomsic M. Ultrasonographic changes of major salivary glands in primary Sjögren's syndrome. Evaluation of a novel scoring system. Eur J Radiol 2007 Sep;63(3):379-83. Epub 2007 Mar 6.

[6] Shimizu M, Okamura K, Yoshiura K, Ohyama Y, Nakamura S. Sonographic diagnosis of Sjögren syndrome: evaluation of parotid gland vascularity as a diagnostic tool. Oral Surg Oral Med Oral Pathol Oral Radiol Endod 2008;106:589-94. 